\section{Commentary: A new Fontan commandment}

\author{
Michael Ma, MD
}

Choussat's Ten Commandments ${ }^{1}$ delineating the appropriate selection criteria for Fontan palliation are well known and carefully regarded among practicing congenital heart surgeons. While many of the criteria have evolved, ventricular performance and the hemodynamic health of the pulmonary vascular bed remain cornerstones of candidacy. Lin and colleagues ${ }^{2}$ share important insights in their study, "Preoperative N-terminal pro-brain natriuretic peptide is associated with Fontan outcomes," and provide compelling data that would suggest adding an 11th commandment to the list.

The retrospective cohort study enrolled all $(\mathrm{n}=110)$ consecutive Fontan recipients in a single center from 2011 to 2019. Although decision-making in the cohort was not influenced by preoperative $\mathrm{N}$-terminal pro-brain natriuretic peptide (NT-BNP) level, this was routinely assayed $(\mathrm{n}=91)$. A variety of preoperative demographic characteristics and variables derived from echocardiography and catheterization data were collected and analyzed for their effect on primary and secondary end points, event-free survival (Fontan takedown, death, transplantation), and heart failure-associated rehospitalizations and postoperative tachyarrhythmia. Via univariate Cox regression, mean pulmonary artery pressure $>15 \mathrm{~mm} \mathrm{Hg}$, pulmonary vascular resistance index, ventricular function (normal vs abnormal), and $\log 10$ NT-BNP showed a significant association, with $\log 10$ NT-BNP surviving as the dominant variable in multivariate regression. This prompted receiver operating characteristic analysis to define a threshold NT-BNP value, of

\footnotetext{
From the Department of Cardiothoracic Surgery, Stanford University School of Medicine, Stanford, Calif.

Disclosures: The author reported no conflicts of interest.

The Journal policy requires editors and reviewers to disclose conflicts of interest and to decline handling or reviewing manuscripts for which they may have a conflict of interest. The editors and reviewers of this article have no conflicts of interest.

Received for publication Dec 23, 2021; revisions received Dec 23, 2021; accepted for publication Jan 5, 2022; available ahead of print Jan 11, 2022.

Address for reprints: Michael Ma, MD, Department of Cardiothoracic Surgery, Falk Cardiovascular Research Center, 300 Pasteur Dr, Stanford, CA 94305 (E-mail: mma@stanford.edu).

J Thorac Cardiovasc Surg 2022;164:783-4

$0022-5223 / \$ 36.00$

Copyright (c) 2022 by The American Association for Thoracic Surgery

https://doi.org/10.1016/j.jtcvs.2022.01.008
}

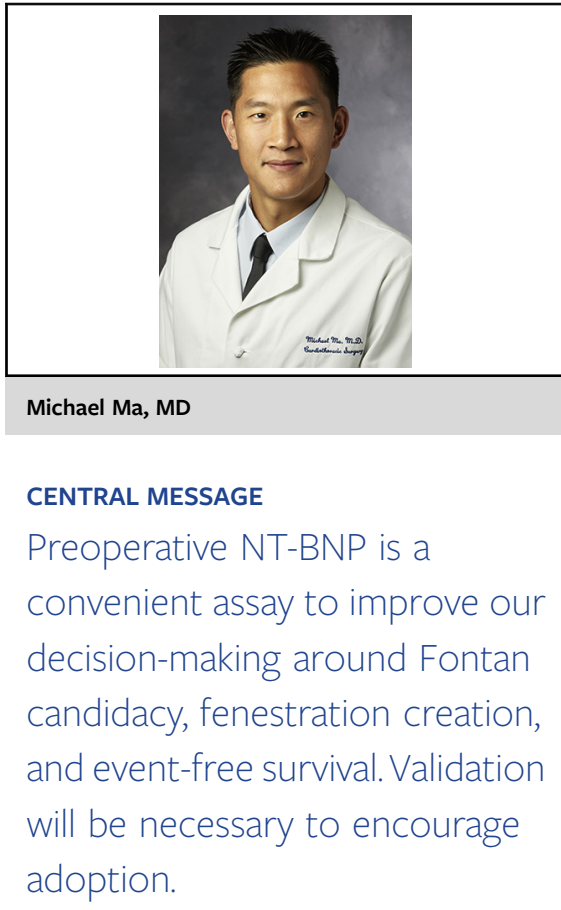

which $280 \mathrm{pg} / \mathrm{mL}$ provided the greatest degree of combined sensitivity $(75 \%)$ and specificity $(71 \%)$. Scoring systems were created, using generally accepted selection criteria (ie, pulmonary artery pressure, pulmonary vascular resistance index) without and with the addition of NT-BNP, and showed an improved ability to predict Fontan failure with NT-BNP. Interestingly, Fontan fenestration was separately assessed in this cohort, with fenestration improving event-free survival for patients with an elevated NT-BNP level preoperatively.

Using a regularly available serum marker as an adjunct to increase predictive power in long-term Fontan survival and candidacy is attractive and certainly convenient. Various groups have had success and failure at correlating ongoing NT-BNP levels with accepted measures of stable Fontan circulation (ventricular function, functional class, exercise capacity). ${ }^{3-5}$ This report presents the first attempt at correlating presurgical NT-BNP levels with post surgical long-term outcomes, and its findings are compelling, with the caveat that nothing is known about the candidates who were not selected for surgery. As the authors mention, their retrospective analysis will certainly require prospective validation. In the meantime, a borderline Fontan candidate with an NT-BNP $>280 \mathrm{pg} / \mathrm{mL}$ would certainly give pause to 
proceeding with surgery, or at a minimum, to including a fenestration during the procedure.

\section{References}

1. Stern HJ. Fontan "Ten Commandments" revisited and revised. Pediatr Cardiol. 2010;31:1131-4.

2. Lin H-C, Huang S-C, Wu M-H, Wang J-K, Lin M-T, Chen C-A, et al. Preoperative $\mathrm{N}$-terminal pro-brain natriuretic peptide is associated with Fontan outcomes. J Thorac Cardiovasc Surg. 2022;164:770-80.e3.
3. Heck PB, Muller J, Weber R, Hger A. Value of N-terminal pro brain natriuretic peptide levels in different types of Fontan circulation. Eur J Heart Fail. 2013; 15:644-9.

4. Wolff D, van Melle JP, Willems TP, Bartelds B, Ploegstra M-J, Hillege H, et al. Nterminal pro-brain natriuretic peptide serum levels reflect attrition of the Fontan circulation. Cardiol Young. 2020;30:753-60.

5. Larsson DA, Meurling CJ, Holmqvist F, Waktare JE, Thilén UJ. The diagnostic and prognostic value of brain natriuretic peptides in adults with a systemic morphologically right ventricle or Fontan-type circulation. Int J Cardiol. 2007; 114:345-51. 